\title{
Preface Special Issue Foundations of Physics
}

\author{
Dennis Dieks • Décio Krause • Christian de Ronde
}

The foundations of quantum mechanics are attracting new and significant interest in the scientific community due to the recent striking experimental and technical progress in the fields of quantum computation, quantum teleportation and quantum information processing. However, at a more fundamental level the understanding and manipulation of these novel phenomena require not only new laboratory techniques but also new understanding, development and interpretation of the formalism of quantum mechanics itself, a mathematical structure whose connection to what happens in physical reality continues to present puzzles and engender debate.

The present issue of Foundations of Physics considers, from physical, philosophical and logical perspectives, a range of problems: these range from the meaning of quantum identity and individuality, through probability and complementarity, to decoherence and gauge theories.

The idea of preparing this special issue was conceived in connection with the Workshop Logical Quantum Structures ${ }^{1}$, organized by Décio Krause and Christian de Ronde, which took place in Rio de Janeiro on 6 and 7 April 2013. The editors trust that the resulting compilation will give new impetus to a number of ongoing debates concerning the foundations of quantum physics.

\footnotetext{
1 The workshop took place as part of the UNILOG World Congress on Universal Logic.

D. Dieks

Utrecht, Netherlands

D. Krause

Florianópolis, Brazil

C. de Ronde $(\varangle)$

Buenos Aires, Argentina

e-mail: cderonde@gmail.com
} 